\title{
Improving the Electropolymerization Properties of Fluorene- Bridged Dicarbazole Monomers through Polyfluoroalkyl Side Chains
}

\author{
Ilir Pecnikaj, Simonetta Orlandi, ${ }^{\circledR}$ and Gianluca Pozzi* \\ Istituto di Scienze e Tecnologie Molecolari del Consiglio Nazionale delle Ricerche, ISTM-CNR, Via Golgi 19, 20133 Milano, Italy \\ María Victoria Cappellari, Gabriela Marzari, Luciana Fernández, Maximiliano Andrés Zensich, ${ }^{(0)}$ \\ Laura Hernandez, and Fernando Fungo*(0)
}

Departamento de Química, Universidad Nacional de Río Cuarto, Agencia Postal 3, X5804BYA Río Cuarto, Argentina

ABSTRACT: The facile functionalization of the fluorene scaffold at the 2,7-positions was utilized to provide access to two soluble carbazole- $\pi$-carbazole derivatives CFC-H1 and CFC-F1 featuring fully hydrogenated and polyfluorinated alkyl chains at the 9position of the fluorene $\pi$-bridging unit, respectively. The optical and electrochemical properties of the new dicarbazoles were investigated. Their electrochemical polymerization over $\mathrm{Pt}$ and indium tin oxide electrodes allowed the generation of electroactive polymeric films, whose physicochemical characteristics were strongly dependent on the kind of alkyl chain present on the fluorene bridge. In particular, the

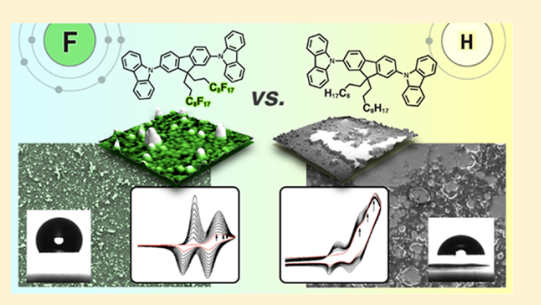
electropolymerization of the polyfluorinated monomer allowed the fabrication of thin films with good electrical conductivity, reversible electrochemical processes, good electrochromic properties, and enhanced water repellency with respect to its nonfluorinated analogue.

\section{INTRODUCTION}

Considerable research efforts are currently devoted to the development of organic macromolecules and polymeric compounds for application in the production of electronic and optoelectronic devices. ${ }^{1-4}$ Actually, a wealth of multifunctional materials with tailored physical characteristics can be obtained from a relatively restricted pool of unsaturated building blocks, thanks to ingenious organic synthesis techniques. ${ }^{5,6}$ It is thus possible to create organic conducting materials with adequate optical and electronic properties, whose utilization can make a great contribution to the advancement of optoelectronic devices such as electrochromic windows, ${ }^{7,8}$ solar cells, ${ }^{9-12}$ and lighting systems. ${ }^{13}$ Inexpensive fluorene and carbazole derivatives are fit to this purpose. Indeed, conjugated materials featuring carbazole units either in the $\pi$-conjugated backbone or as pendant groups display excellent thermal and photochemical stabilities and possess high charge carrier mobility, making them attractive materials for a variety of applications. ${ }^{14-16}$ In an analogous way, fluorene and 9,9'-spirobifluorene derivatives showing high photoluminescence $(\mathrm{PL})$ quantum yields and electroluminescence (EL) efficiencies, as well as high thermal stabilities, have drawn much attention. ${ }^{3,11,17-22}$ Finally, fluorene and carbazole units can be combined in the same molecular structure leading to a variety of compounds with interesting hole transporting and electroluminescence properties. ${ }^{23-27}$

The materials used in the fabrication of optoelectronic devices must provide certain essential characteristics, such as charge transport, strong interaction with light (absorption and/ or emission), chemical stability that avoids material degrada- tion when the device is operating, and a right relative position in the energy scale of the valence band-conduction band regarding the devices contact work function, which ensures the flow of charges in the correct directions. However, for a material to be useful, it must be apt to the formation and deposition of thin films (thicknesses on the order of nanometers), which is a central aspect in the construction of optoelectronic devices. In this context, the electrodeposition of electroactive compounds is an attractive and promising technique for the production of organic material films, since it has the advantage to produce the film in one-step at room temperature, which requires that the monomer is soluble, polymerizable, and that the solubility of the generated polymer is low enough to induce its precipitation on the working electrode. It also has other advantages, such as permitting a fine control of the film thickness, variations of its morphology (e.g., porosity or roughness), an excellent adhesion of the electrodeposited film to the electrode, and the formation of patterns on the film. ${ }^{28}$ In addition, the electropolymerization approach offers unique opportunities to tune the wettability properties of the obtained film by just using judicious chemical modifications of the monomer, although this strategy has been so far applied to a restricted number of monomer cores, such as thiophene and pyrrole derivatives. ${ }^{29-40}$ All of these features are important parameters in the manufacture of optoelectronic devices.

Received: April 19, 2019

Revised: $\quad$ May 28, 2019

Published: June 4, 2019 
In this context, the development of fluorene/carbazole hybrid monomers that can give rise to electrodeposited coatings is particularly appealing. ${ }^{41-45}$ In fact, carbazole and $\mathrm{N}$-substituted carbazoles undergo electrochemical oxidative coupling under relatively low oxidation potential to give nitrogen- and ring-coupled dimers, respectively. ${ }^{46}$ These characteristics enable the deposition of polymeric films over conductive substrates by electrochemical oxidation of monomers bearing at least two carbazole substituents. ${ }^{47-49}$ Thus, electropolymerizable fluorene-based monomers were designed in which the $\mathrm{sp}^{3}$ carbon atom of fluorene (9-position) is connected to the $\mathrm{N}$ atoms of two electroactive carbazole units through flexible alkyl linkers. ${ }^{44,45}$ In this case, efficient polymerization processes could be observed only for monomers containing at least two functionalized fluorene units. $^{44}$ The use of simple $\mathrm{D}-\pi-\mathrm{D}$ conjugated monomers where two carbazole donor groups $\mathrm{D}$ are directly linked to the phenyl rings of the $\pi$-bridging fluorene represents another viable option, ${ }^{43}$ as also shown by early examples of electropolymerizable bipolar 9,9'-spirobifluorene derivatives. $^{41,42}$ Besides ease of synthesis, this approach offers the opportunity to introduce tailored substituents at the 9-position of fluorene, in particular, long alkyl or polyfluoroalkyl chains, which could be used to facilitate the electropolymerization process and to tune the final properties of the electrodeposited material, as previously shown in the case of simple thiophene or pyrrole derivatives. ${ }^{29-40}$

It is well known that the introduction of highly fluorinated moieties in polymeric structures induces valuable features such as improved thermal stability, chemical and oxidative resistance, low dielectric constants, low refractive index, and oil and water repellency. ${ }^{50}$ This last property is crucial for the long-term durability of optoelectronic devices, which is seriously challenged by the deleterious effects of moisture on the charged organic materials produced when the devices are operating. ${ }^{51}$ The optoelectronic characteristics of these fluorinated polymers are also very interesting. As an example, the replacement of hydrogen atoms with fluorine results in lower lowest unoccupied molecular orbital (LUMO) and highest occupied molecular orbital (HOMO) energy states, producing enhanced EL efficiency, whereas the lower HOMO energies are responsible for increased oxidation potentials and enhanced stability against photo-oxidation. ${ }^{52}$ A limited number of conjugated poly- and oligofluorenes bearing poly- or perfluoroalkyl chains at the 9-position have been thus studied, focusing on their PL, EL, and charge transport properties. ${ }^{53-58}$ The surface properties of these compounds, obtained by transition metal-catalyzed cross-coupling reactions preceded by cumbersome multistep syntheses of properly functionalized monomers, were not investigated. It should be also noted that the attempted electropolymerization of fluorene derivatives bearing a single semifluorinated chain at the 9-position failed to give the corresponding polyfluorenes. ${ }^{56}$

Based on these premises, we here report a facile electrochemical polymerization approach to the fabrication of conductive films starting from simple $D-\pi-D$ conjugated carbazole-fluorene-carbazole (CFC) monomers bearing at the 9-position either alkyl- or polyfluoroalkyl chains of similar lengths (Figure 1). It will be shown that the nature of these substituents significantly improves the film formation and affects the morphology, water repellency, and electrochromic behavior of the resulting materials.

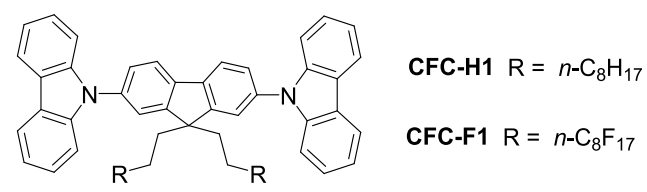

Figure 1. Structure of monomers.

\section{EXPERIMENTAL SECTION}

Synthesis Procedures. General Remarks. All available reagents were purchased from commercial sources and used without any further purification. Solvents were purified by standard methods and dried if necessary. 2,7-Diiodo-9H-fluorene $\mathbf{1}^{59}$ and 9,9-bis$\left(1 \mathrm{H}, 1 \mathrm{H}, 2 \mathrm{H}, 2 \mathrm{H}\right.$-perfluorodecyl)-9H-fluorene $3^{57}$ were prepared as described in the literature. Reactions were monitored by thin-layer chromatography that was conducted on plates precoated with silica gel $\mathrm{Si}$ 60- $\mathrm{F}_{254}$ (Merck, Germany). Column chromatography was carried out on silica gel SI 60 (Merck, Germany), mesh size 0.063$0.200 \mathrm{~mm}$ (gravimetric) or $0.040-0.063 \mathrm{~mm}$ (flash). ${ }^{1} \mathrm{H}$ NMR and ${ }^{13} \mathrm{C}$ NMR were recorded on a Bruker Avance 400 spectrometer (400 and $100.6 \mathrm{MHz}$, respectively); ${ }^{19} \mathrm{~F}$ NMR spectra were recorded on a Bruker AC 300 spectrometer $(282 \mathrm{MHz})$. Elemental analyses were carried out by the Departmental Service of Microanalysis (University of Milano).

9,9-Didecyl-2,7-diiodo-9H-fluorene (2). Powder $\mathrm{KOH}$ (1.00 g, $17.9 \mathrm{mmol}$ ) was added to a stirred solution of 2,7-diiodo-9H-fluorene $1(1.67 \mathrm{~g}, 4.0 \mathrm{mmol})$ in dimethyl sulfoxide $(15 \mathrm{~mL})$ under a nitrogen atmosphere. After $5 \mathrm{~min}, \mathrm{KI}(0.12 \mathrm{~g}, 0.7 \mathrm{mmol})$ was added, followed by 1-bromodecane $(2.65 \mathrm{~g}, 12.0 \mathrm{mmol})$. The reaction mixture was stirred under nitrogen for $15 \mathrm{~h}$ at RT, and then, it was poured into $\mathrm{H}_{2} \mathrm{O}(100 \mathrm{~mL})$. The aqueous phase was extracted with $\mathrm{Et}_{2} \mathrm{O}(3 \times 30$ $\mathrm{mL}$ ). The combined organic phases were dried over $\mathrm{MgSO}_{4}$ and evaporated under reduced pressure. The residue was purified by column chromatography (silica gel, petroleum ether) to give the bis alkylated fluorene 2 as a pale yellow oil $(1.90 \mathrm{~g}, 68 \%) .{ }^{1} \mathrm{H}$ NMR (400 $\left.\mathrm{MHz}, \mathrm{CDCl}_{3}\right) \delta 7.67-7.60(\mathrm{~m}, 4 \mathrm{H}), 7.40(\mathrm{~d}, J=8.4 \mathrm{~Hz}, 2 \mathrm{H}), 1.91-$ $1.86(\mathrm{~m}, 4 \mathrm{H}), 1.29-1.05(\mathrm{~m}, 28 \mathrm{H}), 0.86(\mathrm{t}, J=6.6 \mathrm{~Hz}, 6 \mathrm{H}), 0.63-$ $0.52(\mathrm{~m}, 4 \mathrm{H}) ;{ }^{13} \mathrm{C} \mathrm{NMR}\left(101 \mathrm{MHz}, \mathrm{CDCl}_{3}\right) \delta 152.51,139.77$, $136.03,132.03,121.52,93.16,55.56,40.10,31.91,29.88,29.55$ $\left(2 \mathrm{CH}_{2}\right), 29.32,29.21,23.65,22.71,14.17$. Anal. calcd for $\mathrm{C}_{33} \mathrm{H}_{48} \mathrm{I}_{2}: \mathrm{C}$, 56.74; H, 6.93; found: C, 56.81; H, 7.03.

9,9-Bis(3,3,4,4,5,5,6,6,7,7,8,8,9,9,10,10,10-heptadecafluorodecyl)-2,7-diiodo-9H-fluorene (4). A $25 \mathrm{~mL}$ round-bottom flask equipped with a magnetic stir bar and a reflux condenser was charged with fluorene derivative $3(1.06 \mathrm{~g}, 1.0 \mathrm{mmol})$, iodine $(0.19 \mathrm{~g}$, $0.75 \mathrm{mmol})$, iodic acid $(0.09 \mathrm{~g}, 0.5 \mathrm{mmol})$, water $(0.3 \mathrm{~mL})$, acetic acid $(7 \mathrm{~mL})$, and $98 \% \mathrm{H}_{2} \mathrm{SO}_{4}(0.06 \mathrm{~mL})$. The mixture was heated under reflux for $4 \mathrm{~h}$ under vigorous stirring, and then, it was cooled to RT. The white precipitate formed was filtered off, washed with water, and dried under vacuum. It was then dissolved in the minimal amount of $\mathrm{CH}_{2} \mathrm{Cl}_{2}$ and reprecipitated by adding dry ethanol. The crude compound was further purified by column chromatography (silica gel, hexane) to give the title compound as a white solid (1.02 g, 78\% yield). mp $117-118{ }^{\circ} \mathrm{C} ;{ }^{1} \mathrm{H}$ NMR $\left(400 \mathrm{MHz}, \mathrm{CDCl}_{3}\right) \delta 7.77$ (d, $J=$ $8.0 \mathrm{~Hz}, 2 \mathrm{H}), 7.69(\mathrm{~s}, 2 \mathrm{H}), 7.47(\mathrm{~d}, J=8.0 \mathrm{~Hz}, 2 \mathrm{H}), 2.41-2.17(\mathrm{~m}$, $4 \mathrm{H}), 1.36-1.18(\mathrm{~m}, 4 \mathrm{H}) ;{ }^{13} \mathrm{C}$ NMR $\left(101 \mathrm{MHz}, \mathrm{CDCl}_{3}\right) \delta 148.01$, $139.76,137.12,131.73,122.05,120.57-107.19\left(\mathrm{~m}, \mathrm{C}_{8} \mathrm{~F}_{17}\right), 93.52$, $54.93,30.15,26.14\left(\mathrm{t}, J_{\mathrm{CF}}=22 \mathrm{~Hz}\right) ;{ }^{19} \mathrm{~F}$ NMR $\left(377 \mathrm{MHz} \mathrm{CDCl}_{3}\right) \delta$ $-81.73(\mathrm{t}, J=9.6 \mathrm{~Hz}, 6 \mathrm{~F}),-115.36(\mathrm{~s}, 4 \mathrm{~F}),-122.60$ to $-123.10(\mathrm{~m}$, $12 \mathrm{~F}),-123.71(\mathrm{~s}, 4 \mathrm{~F}),-124.76(\mathrm{~s}, 4 \mathrm{~F}),-127.10(\mathrm{~s}, 4 \mathrm{~F})$. Anal. calcd for $\mathrm{C}_{33} \mathrm{H}_{14} \mathrm{~F}_{34} \mathrm{I}_{2}$ : C, 30.25; H, 1.08; found: C, 30.13; H, 1.12.

9,9'-(9,9-Didecyl-9H-fluorene-2,7-diyl)bis(9H-carbazole) (CFCH1). A flame-dried Schlenk tube equipped with a stir bar was charged with fluorene $2(1.40 \mathrm{~g}, 2.0 \mathrm{mmol})$, carbazole $(1.00 \mathrm{~g}, 6.0$ $\mathrm{mmol})$, dry $\mathrm{K}_{2} \mathrm{CO}_{3}(1.24 \mathrm{~g}, 9.0 \mathrm{mmol})$, copper bronze $(0.77 \mathrm{~g}, 12.0$ $\mathrm{mmol}), 18$-crown-6 (0.16 g, $0.6 \mathrm{mmol})$, and dry 1,2-dichlorobenzene $(15 \mathrm{~mL})$ under a nitrogen atmosphere. The reaction mixture was deaerated by freeze-pump-thaw cycles (three times), purged with nitrogen, and heated at $180{ }^{\circ} \mathrm{C}$ under stirring for $48 \mathrm{~h}$. The mixture 


\section{Scheme 1. Synthesis of CFC Monomers}

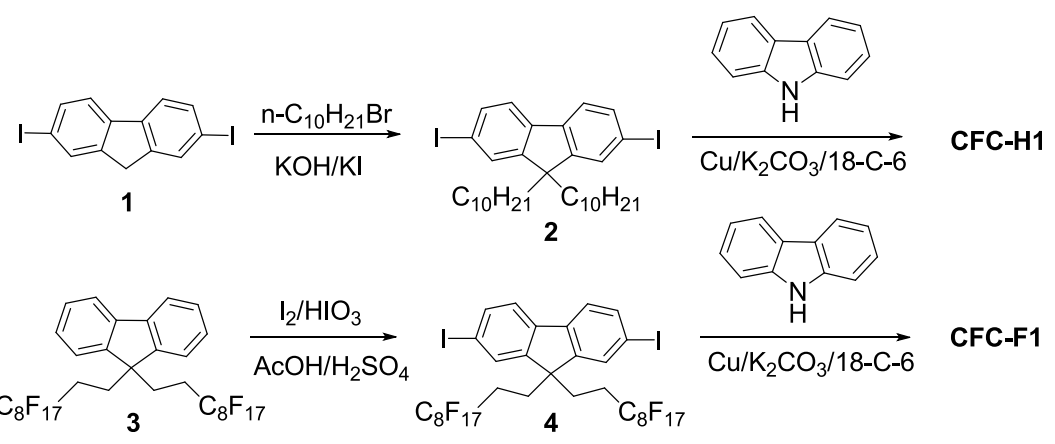

was cooled to RT, diluted with dichloromethane (DCM) $(30 \mathrm{~mL})$, and filtered through a short pad of Celite. The organic solvents were removed by evaporation under vacuum, and the residue was purified by flash column chromatography (silica gel, petroleum ether/DCM $10 / 1)$. The title compound was obtained as an off-white glassy solid (1.46 g, 94\% yield). ${ }^{1} \mathrm{H}$ NMR (400 $\left.\mathrm{MHz}, \mathrm{CDCl}_{3}\right) \delta 8.19$ (d, $J=7.8$ $\mathrm{Hz}, 4 \mathrm{H}), 7.99(\mathrm{~d}, J=7.8 \mathrm{~Hz}, 2 \mathrm{H}), 7.65-7.57(\mathrm{~m}, 4 \mathrm{H}), 7.51-7.42(\mathrm{~m}$, $8 \mathrm{H}), 7.33$ (ddd, $J=7.9,6.5,1.7 \mathrm{~Hz}, 4 \mathrm{H}), 2.08-1.99$ (m, 4H), 1.36$1.05(\mathrm{~m}, 28 \mathrm{H}), 0.91-0.96(\mathrm{~m}, 4 \mathrm{H}), 0.83(\mathrm{t}, J=6.9 \mathrm{~Hz}, 6 \mathrm{H}) ;{ }^{13} \mathrm{C}$ NMR $\left(101 \mathrm{MHz}, \mathrm{CDCl}_{3}\right) \delta 152.89,140.99,139.55,136.70,125.96$ $(2 \mathrm{CH}), 123.41,121.86,121.03,120.42,119.95,109.77,55.72,40.23$, $31.88,30.03,29.61,29.56,29.42,29.28,24.18,22.65,14.11$. Anal. calcd for $\mathrm{C}_{57} \mathrm{H}_{64} \mathrm{~N}_{2}$ : C, 88.09; H, 8.30; N, 3.60; found: C, 88.15; H, 8.46; N, 3.49.

9, $9^{\prime}$-(9,9-Bis $(3,3,4,4,5,5,6,6,7,7,8,8,9,9,10,10,10$-heptadecafluorodecyl)-9H-fluorene-2,7-diyl)bis(9H-carbazole) (CFC-F1). A flamedried Schlenk tube equipped with a magnetic stir bar was charged with fluorene $4(1.31 \mathrm{~g}, 1.0 \mathrm{mmol})$, carbazole $(0.50 \mathrm{~g}, 3.0 \mathrm{mmol})$, dry $\mathrm{K}_{2} \mathrm{CO}_{3}(1.07 \mathrm{~g}, 5.0 \mathrm{mmol})$, copper bronze $(0.38 \mathrm{~g}, 6.0 \mathrm{mmol})$, 18crown-6 $(79 \mathrm{mg}, 0.3 \mathrm{mmol})$, and dry 1,2-dichlorobenzene $(10 \mathrm{~mL})$ under nitrogen atmosphere. The reaction mixture was deaerated by freeze-pump-thaw cycles (three times), purged with nitrogen, and heated at $180{ }^{\circ} \mathrm{C}$ under stirring for $60 \mathrm{~h}$. The mixture was cooled to RT, diluted with DCM $(30 \mathrm{~mL})$, and filtered through a short pad of Celite. The organic solvents were removed by evaporation under vacuum, and the crude product was purified by flash column chromatography (silica gel, petroleum ether/DCM 6/1). The fractions containing the products were collected and evaporated to dryness, and the residue was recrystallized from hexane to give the title compound as a white solid $(0.87 \mathrm{~g}, 63 \%$ yield $) . \mathrm{mp} 89-90{ }^{\circ} \mathrm{C}$; ${ }^{1} \mathrm{H}$ NMR $\left(400 \mathrm{MHz}, \mathrm{CD}_{2} \mathrm{Cl}_{2}\right) \delta 8.20(\mathrm{~d}, J=7.8 \mathrm{~Hz}, 4 \mathrm{H}), 8.11(\mathrm{~d}, J=$ $8.0 \mathrm{~Hz}, 2 \mathrm{H}), 7.76(\mathrm{dd}, J=8.0,1.8 \mathrm{~Hz}, 2 \mathrm{H}), 7.72(\mathrm{~d}, J=1.7 \mathrm{~Hz}, 2 \mathrm{H})$, $7.48-7.43(\mathrm{~m}, 8 \mathrm{H}), 7.37-7.30(\mathrm{~m}, 4 \mathrm{H}), 2.57-2.36(\mathrm{~m}, 4 \mathrm{H}), 1.77-$ $1.54(\mathrm{~m}, 4 \mathrm{H}) .{ }^{13} \mathrm{C}$ NMR $\left(101 \mathrm{MHz}, \mathrm{CD}_{2} \mathrm{Cl}_{2}\right) \delta 148.98,141.37$, $140.14,138.45,128.17,126.64,124.07,122.71,122.01,120.94$, $120.82,110.11,120.91-107.51\left(\mathrm{~m}, \mathrm{C}_{8} \mathrm{~F}_{17}\right), 55.86,30.85,26.80\left(\mathrm{~d}, J_{\mathrm{CF}}\right.$ $=22 \mathrm{~Hz}) ;{ }^{19} \mathrm{~F} \mathrm{NMR}\left(377 \mathrm{MHz}, \mathrm{CDCl}_{3}\right) \delta-81.71(\mathrm{t}, J=9.6 \mathrm{~Hz}, 6 \mathrm{~F})$, -115.42 (s, 4F), -122.60 to $-123.04(\mathrm{~m}, 12 \mathrm{~F}),-123.69(\mathrm{~s}, 4 \mathrm{~F})$, $-124.60(\mathrm{~s}, 4 \mathrm{~F}),-127.08$ (s, 4F). Anal. calcd for $\mathrm{C}_{57} \mathrm{H}_{30} \mathrm{~F}_{34} \mathrm{~N}_{2}$ : C, 49.29; H, 2.18, N, 2.02; found: C, 49.18; H, 2.22, N, 1.96 .

Optical and Electrochemical Characterization of Monomers and Polymers Films. For the optical characterization, a diode array HP 8452 spectrometer and a Spex FluoroMax fluorometer were used to measure the absorption and fluorescence spectra, respectively. Spectra in 1,2-dichloroethane (DCE) solution were acquired at room temperature using $1 \mathrm{~cm}$ path length quartz cells.

The voltammetric characterization of the redox processes and electropolymerization of the monomers were performed with a $\mathrm{CH}$ Instruments $700 \mathrm{E}$ pontentiostat using a silver wire quasi-reference electrode and a loop $\mathrm{Pt}$ as a counterelectrode in a conventional threeelectrode cell. A Pt disk ( $2 \mathrm{~mm}$ in diameter), polished on a felt pad with $0.3 \mu \mathrm{m}$ alumina and sequentially sonicated in water and absolute ethanol, was used as a working electrode for the voltammetric characterization of the redox processes, and indium tin oxide (ITO) electrodes (Delta Technologies) were used for electropolymerization.
Electrochemical studies of monomers were carried out in DCE with $0.10 \mathrm{M}$ tetra- $n$-butylammonium hexafluorophosphate $\left(\mathrm{TBAPF}_{6}\right)$ as the supporting electrolyte. All of the electrochemical responses of the electropolymerized films were obtained in DCE solution with 0.10 $\mathrm{M} \mathrm{TBAPF}_{6}$ as the supporting electrolyte. A silver wire quasi-reference electrode was calibrated using a ferrocenium/ferrocene $\left(\mathrm{Fc}^{+} / \mathrm{Fc}\right)$ couple with potential $\mathrm{Fc}^{+} / \mathrm{Fc}$ taken as $0.4 \mathrm{~V}$ versus a saturated calomel electrode. $^{60}$

Spectroelectrochemical experiments were carried out in a homemade cell built from a commercial UV-visible cuvette. The ITOcoated glass was used as the working electrode; a Pt wire was used as the counterelectrode, and an $\mathrm{Ag}$ wire was used as the reference electrode. These experiments were carried out in DCE with $0.10 \mathrm{M}$ $\mathrm{TBAPF}_{6}$ as the supporting electrolyte. The cell was placed in the optical path of the sample light beam. The background correction was obtained by taking an UV-vis spectrum of a blank cell (an electrochemical cell with an ITO working electrode without the polymer film) with conditions and parameters identical to those of the polymer experiment.

Scanning electron microscopy (SEM) micrographs were collected using a Carl Zeiss EVO MA 10 SEM, with electron beam energy of 18 $\mathrm{keV}$.

Atomic force microscopy (AFM) characterization of the polymer films on ITO electrodes was performed using an Agilent 5500 SPM microscope (Agilent Technologies, Inc.) working in acoustic AC mode. Commercial silicon cantilever probes, with aluminum backside coating and a nominal tip radius of $10 \mathrm{~nm}$ (MikroMasch, NSC15/Al $\mathrm{BS} / 15$, spring constant ranging $20-75 \mathrm{~N} / \mathrm{m}$ ), were employed just under their fundamental resonance frequencies of about $325 \mathrm{kHz}$. The experiments were performed in a stationary dry-air atmosphere. Images were treated and analyzed using Gwyddion, an open source software for the visualization and analysis of scanning probe microscopy data.

Contact angle measurements were performed using an optical contact angle meter (Attension Theta optical tensiometer) at room temperature and humidity. A Milli-Q water droplet (droplet size: 5 $\mu \mathrm{L})$ was placed with a Hamilton syringe $(25 \mu \mathrm{L})$ on the surface of the electrodeposited films. The contact angles reported values are the averages of at least three consecutive measurements (three water droplets). Samples for contact angle measurements were prepared using the same procedure as those used for spectroelectrochemistry onto an ITO, and they were washed with solvent to eliminate the electrolyte that could remain on the electrode.

\section{RESULTS AND DISCUSSION}

Synthesis of CFC Monomers. The polyfluorinated monomer CFC-F1 and its fully hydrogenated analogue CFC-H1 were synthesized starting from 2,7-diodofluorene 1 and 9,9-bis $(1 H, 1 H, 2 H, 2 H$-perfluorodecyl)-9H-fluorene 3 , respectively, according to the straightforward two-step sequences outlined in Scheme 1. The introduction of two $n$-decyl chains at the 9-position of $\mathbf{1}$ to give the CFC-H1 precursor $\mathbf{2}$ was easily achieved by the nucleophilic substitution reaction with 
1-bromodecane in the presence of a substoichiometric amount of $\mathrm{KI}$. An excess of $\mathrm{KOH}$ was used to generate the nucleophilic 9-fluorenyl anions. A slightly different route had to be employed to get good yields of the desired polyfluorinated intermediate 4 . In that case, the fluorene derivative 3 was first synthesized, followed by iodination of the 2,7-positions of the fluorene scaffold.

Indeed, attempts at introducing two $\mathrm{C}_{8} \mathrm{~F}_{17}\left(\mathrm{CH}_{2}\right)_{2}-$ chains at the 9-position of $\mathbf{1}$ were frustrated by the massive occurrence of side reactions favored by the strong electronwithdrawing character of the $-\mathrm{C}_{8} \mathrm{~F}_{17}$ group. ${ }^{57} \mathrm{Bis} \mathrm{N}$-arylation of intermediates $\mathbf{2}$ and $\mathbf{3}$ with carbazole was then performed under mild Ullmann-type conditions, affording CFC-H1 and CFC-F1, respectively, in excellent yields.

Optical Properties of CFC Monomers. The electronic transitions of CFC-H1 and CFC-F1 were investigated by measuring their absorption and emission spectra in diluted DCE solutions. The obtained results are shown in Figure 2,

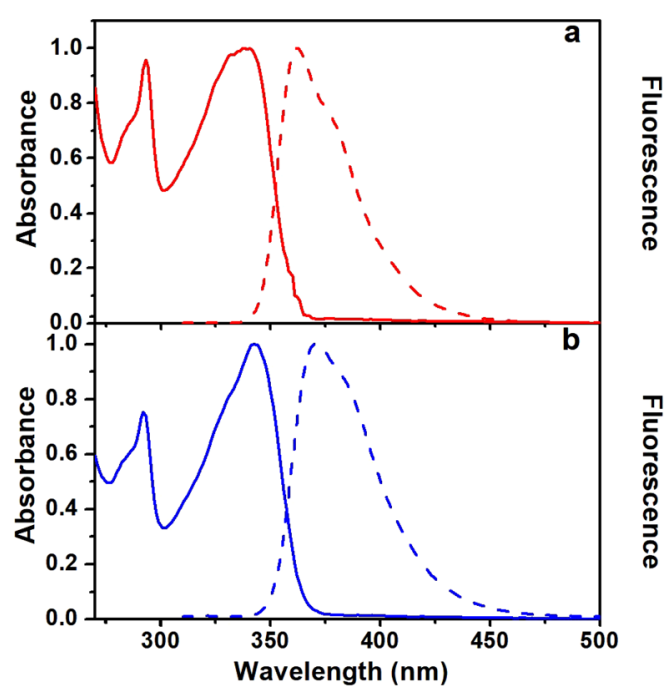

Figure 2. Absorption (solid line) and emission (dot line) spectra of CFC-H1 (red) and CFC-F1 (blue), recorded in DCE solution. The emission spectra were taken with excitation at $338 \mathrm{~nm}$ for CFC-H1 and $342 \mathrm{~nm}$ for CFC-F1.

and the main photophysical parameters are summarized in Table 1. A comparison of both spectra shows almost identical optical transition features, which indicates that the insertion of fluorinated alkyl chains at the 9-position of fluorene does not affect the conjugated core of the chromophore system. CFC monomers exhibit two clear absorptions bands at $\sim 290$ and $\sim 340 \mathrm{~nm}$. The light absorption at $290 \mathrm{~nm}$ is due to the $\pi-\pi^{*}$ electron transition of the carbazole moiety, whereas the lowerenergy transition is assigned to electron transfer from nitrogen lone pairs to the $\pi^{*}$ orbital of fluorene. ${ }^{20,24,43,61-64}$ As reported in Table 1 , the $\pi-\pi^{*}$ electron transition occurs at the same wavelength for both dyes, as the torsion that allows the $\sigma$ bonding between the carbazole and fluorene moieties minimizes the extension of the conjugation length between the two aromatic centers. On the other hand, the band assigned to the electron transfer processes between carbazole and fluorene is $4 \mathrm{~nm}$ shifted toward lower energy for CFC-F1 with respect to CFC-H1, which indicates the existence of a residual inductive effect exerted by the polyfluorinated alkyl chains.

The photoluminescence properties of CFC-H1 and CFC-F1 were studied in DCE solution by exciting the monomers at the wavelength maximum of the lower-energy light absorption band. As shown in the dyes emission spectra reported in Figure 2, CFC-H1 and CFC-F1 emit light at 363 and $370 \mathrm{~nm}$ with quantum yields of 0.77 and 0.69 , respectively. On the other hand, it was observed that the fluorescence excitation spectra of CFC dyes at different excitation energies were superimposable to their absorption spectra, and in addition, a unique fluorescence emission spectrum was obtained irrespective of the excitation wavelength. These results support the absence of light-emitting impurities in the CFC dye solution.

Electrochemical Properties of CFC Monomers: Electropolymerization and Film Formation. Cyclic voltammetry experiments were carried out to obtain information about the electrochemical processes of the monomers and their capability to form electropolymers. The results obtained are shown in Figure 3. It is interesting to note that CFC molecular structures are similar, the only difference being the nature of the saturated chains $\left(\mathrm{C}_{10} \mathrm{H}_{21}-\right.$ or $\left.\mathrm{C}_{8} \mathrm{~F}_{17}\left(\mathrm{CH}_{2}\right)_{2}-\right)$ in the 9position of the fluorene moiety (Figure 1). Since the fluorinated chain in CFC-F1 is linked to the fluoreneconjugated center of the system by a nonconjugated bridge, a small influence of the inductive effect on the electrochemical behavior of the dye was expected, similarly to what was observed in photophysical studies. However, a general inspection of the CFC cyclic voltamperogram shapes presented in Figure 3aI,bI shows remarkable differences in the behavior

Table 1. Photophysical and Electrochemical Parameters of the Compounds

\begin{tabular}{|c|c|c|c|c|c|c|c|c|c|}
\hline \multirow[b]{2}{*}{ compd } & \multicolumn{2}{|c|}{ absorption } & \multicolumn{2}{|c|}{ emission } & \multicolumn{2}{|c|}{ oxidation potentials } & \multicolumn{3}{|c|}{ energy levels $f$} \\
\hline & $\lambda_{\text {mono }}(\mathrm{nm})^{a}$ & $\lambda_{\text {film }}^{\text {onset }}(\mathrm{nm})^{b}$ & $\lambda_{\text {mono }}(\mathrm{nm})^{a}$ & $\phi_{\mathrm{em}}{ }^{c}$ & $E_{\text {mono }}(\mathrm{V})^{d}$ & $E_{\text {film }}(\mathrm{V})^{e}$ & HOMO $(\mathrm{eV})$ & LUMO (eV) & $E_{\mathrm{g}}(\mathrm{eV})$ \\
\hline CFC-H1 & $\begin{array}{l}292 \\
338\end{array}$ & 397 & 363 & 0.77 & $\begin{array}{l}0.81 \\
0.96 \\
1.06\end{array}$ & 0.43 & -5.53 & -2.41 & 3.12 \\
\hline CFC-F1 & $\begin{array}{l}292 \\
342\end{array}$ & 404 & 370 & 0.69 & $\begin{array}{l}0.84 \\
0.95\end{array}$ & 0.44 & -5.54 & -2.47 & 3.07 \\
\hline
\end{tabular}

${ }^{a}$ Spectra measured in DCE. The emission spectra were measured by excitation at the maximum wavelength of the lower-energy absorption bands. ${ }^{b}$ Low-energy optical onset of the electrodeposited films, as determined from the intersection between the projection of the corresponding spectrum in the reduced state and the baseline. ${ }^{c}$ Emission quantum yield obtained in DCE. The standard used was 9,10 -diphenylanthracene. $\phi_{\mathrm{FL}}$ (9,10diphenylanthracene) $=1$ in cyclohexane. ${ }^{65} d$ Peak potential. ${ }^{e}$ Onset potentials of the electrodeposited films determined from intersection between the baseline and the current signal. The potentials values are expressed in volt vs $\mathrm{Fc} / \mathrm{Fc}^{+} .{ }^{f} \mathrm{Calculated} \mathrm{HOMO}$ and LUMO energies of the films in the absolute scale $(\mathrm{eV})$ as obtained using the following equations: $\mathrm{HOMO}=-\left(E_{\mathrm{film}}+5.1\right), \mathrm{LUMO}=-\left(E_{\mathrm{g}}-\mathrm{HOMO}\right)$ and $E_{\mathrm{g}}=1240 / \lambda_{\text {film }}^{\text {onset }} \cdot 60$ 

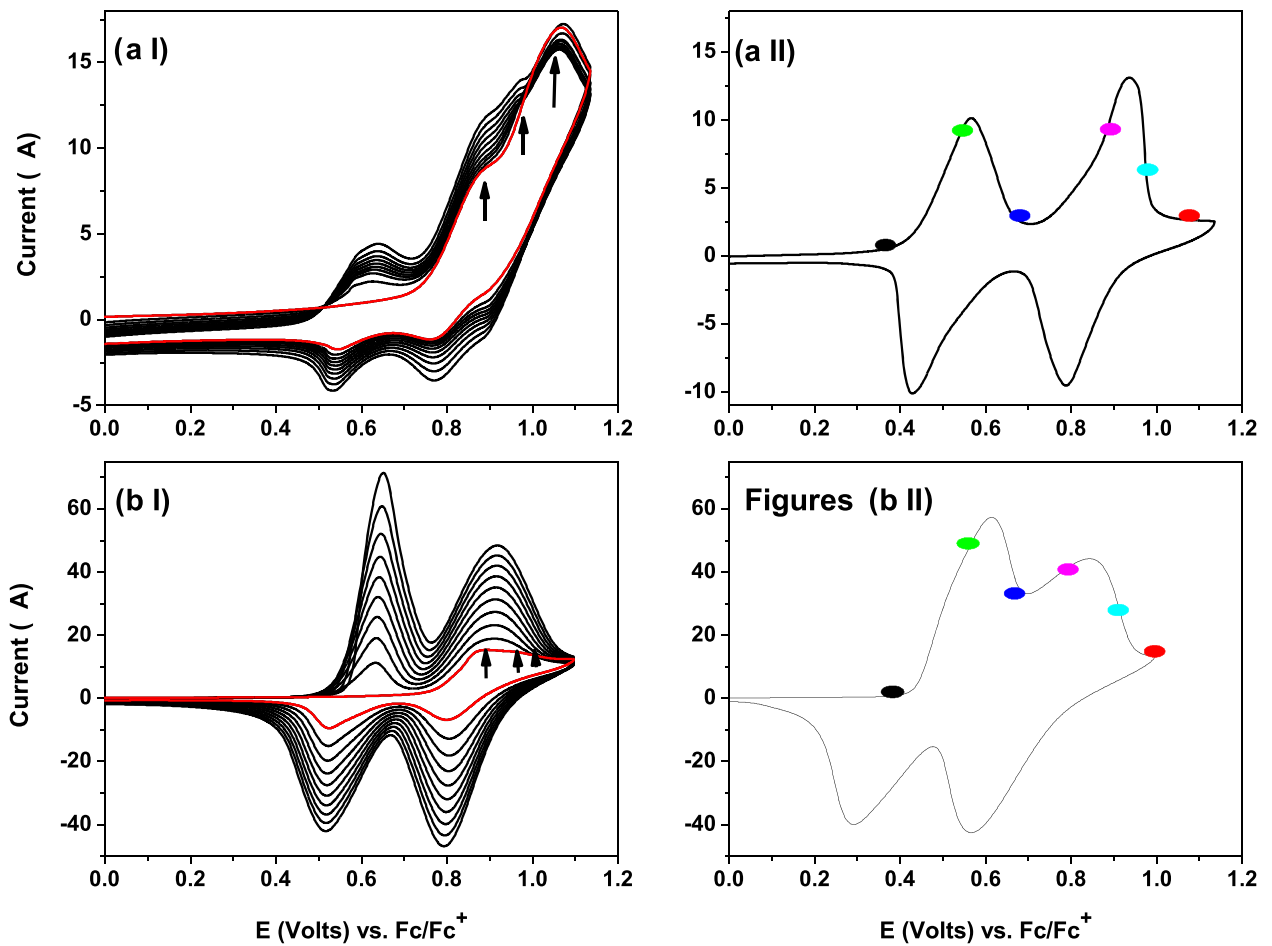

Figure 3. First (red) and 2nd-10th (black) cyclic voltammograms of CFC-H1 (aI) and CFC-F1 (bI). Electrochemical response of the CFC-H1 (aII) and CFC-F1 (bII) electrodeposited films. Conditions: Pt working electrode, electrolyte $\mathrm{TBAPF}_{6} 0.1 \mathrm{M}$ solution in DCE, $v=0.1 \mathrm{~V} / \mathrm{s}$.

of the two monomers, which indicates that the introduction of fluorinated chains notably affects the CFC redox properties. The cyclic voltammograms of CFC dyes measured on a freshly polished $\mathrm{Pt}$ electrode show three oxidation processes in the first scan to positive potentials (red line) around $0.85,0.95$, and $1.00 \mathrm{~V}$. In the case of CFC-H1, the detected first and second oxidation processes are manifested as a shoulder of a wave with a maximum at $1.06 \mathrm{~V}$ (see arrows in Figure 3aI), whereas for CFC-F1, these redox processes are not so well defined as in the case of CFC-H1 and they overlap in a wave with a maximum at $0.88 \mathrm{~V}$ (see arrows in Figure $3 \mathrm{bI}$ ). Afterward, when the potential scan direction is inverted, complementary reduction waves to the previous oxidation processes are detected, at 0.78 and $0.91 \mathrm{~V}$ for CFC-H1, at 0.81 $\mathrm{V}$ for CFC-F1, and another at $0.54 \mathrm{~V}$ for both CFCs dyes (see Figure 3aI,bI). During the second cycle, a new oxidation peak at $0.62 \mathrm{~V}$ is identified regarding the first potential swept, which is complementary to the reduction process observed at $0.54 \mathrm{~V}$ in the first cathodic sweep (see the black line in Figure 3aI,bI). Finally, when the electrode potential is continually cycled (see the black line in Figure 3aI,3bI) in both molecular systems, all of the voltamperogram current waves show a progressive growth, but with a different rate. Clearly, the CFC-F1 current growth rate is bigger than that of CFC-H1. This behavior can be ascribed to the development of a conductive and electroactive film on the working electrode surface. In concordance, when the electrodes were removed from the electrochemical cell, washed with fresh solvent to eliminate any rest of monomer, and then transferred to a monomer-free supporting electrolyte solution, electrochemical signals characteristic of redox-active-modified electrodes were observed (Figure 3aII,bII).

The cyclic voltammograms of the CFC-H1 and CFC-F1 electrodeposited films show two oxidation waves with peak potentials at $0.57 / 0.93$ and $0.62 / 0.85 \mathrm{~V}$, respectively.
However, as previously pointed out, CFC-F1 is much more efficient than CFC-H1 in terms of the film electrodeposition rate. This is clearly shown in Figure 3, where on applying 10 potential scan cycles in equal experimental conditions, CFC-F1 presents a bigger current increment between successive voltamperometric cycles producing a 4 times more film oxidation current than that of CFC-H1, which can be associated with a greater amount of electrodeposited material on the electrode surface.

For both CFC monomers, the first oxidation signal observed in the first potential scan (see the red line and inserted arrows in Figure 3aI,bI) can be assigned to the oxidation of the fluorene ring, whereas the second and third electrochemical signals are the oxidation of each carbazole units. The oxidation of the second carbazole moiety occurs at a more anodic potential because a higher Coulombic attraction must be overcome to remove a third electron from the dicationic charged species formed in the previous oxidation steps. ${ }^{20}$ The reactive 2,7-positions of the fluorene core in the CFCs dyes are blocked by two nitrogen atoms, which stabilize the cation radical. In fact, when the potential is swept until the beginning of the first oxidation wave, where the carbazole units are not oxidized, the current growth with the number of potential sweep cycles is not observed. In addition, it is observed that the CFC-F1 first oxidation process is $30 \mathrm{mV}$ shifted to more anodic potentials with respect to CFC-H1 (see Table 1), evidencing a fluorinated chain effect on the fluorene ring. On the other hand, as it is shown in Figure 3aI,bI, when the scan potential reaches the second oxidation process, the typical electrodeposition process stimulated by coupling of two carbazole cation radicals starts. ${ }^{41,42,48,49}$ Indeed, the oxidation of one carbazole center leads to the formation of a radical cation that undergoes a dimerization reaction to produce less soluble dicarbazole, which precipitates on the electrode surface forming a polymeric film. ${ }^{46,47}$ 
It is known that the carbazole dimer structural motif allows the extension of the conjugation length compared to the single carbazole unit, which makes the dimer obtained in the first step of the electropolymerization process more easily oxidizable than the starting monomer. ${ }^{24,41,42,46,48,49}$ Thus, the carbazole dimer produces new voltamperometric signals in the second potential scan cycle around 0.62 and $0.90 \mathrm{~V}$, corresponding to its radical cation and dication (see Figure 3). Consequently, the oxidation wave of the dimer dication overlaps with the ones corresponding to the starting CFC monomers, masking their electrochemical signals. For CFC-F1, which shows a higher electrodeposition rate, this effect is manifest, producing changes in the current magnitude of the monomer oxidation peaks and, therefore, changes in the voltammograms shape in the first potential scan regarding CFC-H1 (see the red line in Figure 3aI,bI).

The CFC films showed high stability when they were subjected to several oxidation-reduction cycles, and their redox behavior is comparable to that observed with other carbazole derivatives. ${ }^{41,42,48}$ However, the comparative analysis of the electrochemical data clearly demonstrates the unexpected role played by the pendant polyfluoroalkyl chains, which improves enormously the film electroformation in the case of CFC-F1. This effect cannot be ascribed to any electronic effect, but rather to the well-known deviation of the solubility properties of compounds featuring polyfluoroalkyl chains from those of their nonfluorinated analogues. ${ }^{66,67}$ In general, the higher the number of polyfluoroalkyl substituents, the lower the affinity of the compound for standard organic solvents. Thus, the presence of four $\mathrm{C}_{8} \mathrm{~F}_{17}\left(\mathrm{CH}_{2}\right)_{2}-$ chains in the dimeric form of CFC-F1 produced in the first scan favors the separation of this product from the organic solvent and the precipitation on the electrode, which is not the case for the fully soluble dimeric form of CFC-H1. The same happens for the oligomeric forms of CFC-F1 generated in the subsequent scans, with the result of an increased rate of formation of the polymeric film on the electrode. Rigidity of the terminal $\mathrm{C}_{8} \mathrm{~F}_{17}$ groups might also play a role, by enhancing the microstructural ordering of the fluorinated polymer. ${ }^{68}$

Morphological and Surface Properties of Electrodeposited Films. The morphological characteristics of the film surface are a significant parameter associated with the possible use of organic materials as active layers in optoelectronic and electronic devices. ${ }^{25,67}$ Figure 4 shows SEM images of the surfaces of CFC-H1 and CFC-F1 electropolymer films obtained under the same experimental conditions used in the electrochemical studies described above. Despite the identical deposition method used, the different surface characteristics of the two films are blatant.

The CFC-H1 film is uneven, and it does not cover the ITO electrode surface showing unfilled spaces. On the contrary, the CFC-F1 polymeric structure shows a granulate aspect and homogeneously full coats the outside of the ITO electrode. The morphology of the CFC-F1 film surface shows that its formation goes through a nucleation and growth process that ends up in the formation of a continuous film with globularshaped features. Thus, the observed film surface differences between the two modified electrodes are in agreement with the highest CFC-F1 electrodeposition rate regarding CFC-H1, which allows us to electrodeposit, in a homogenous way, a greater amount of material on the electrode surface. Moreover, as can be seen in Figure 4, the aspect of the CFC electrode surface morphological images obtained by AFM corroborates
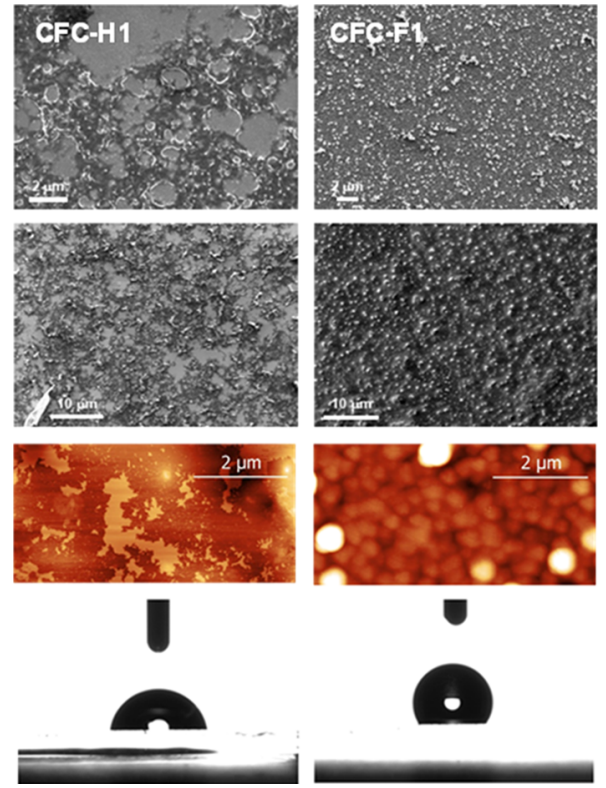

Figure 4. Up to down: Scanning electron and atomic force microscopy images and digital camera photographs of a water droplet on the film surface obtained by applying 10 growth cycles. Left, CFCH1; right, CFC-F1.

their surface characteristic found in the SEM study. The AFM images exhibit that the CFC-H1-modified ITO electrode has a nonuniform and crannied surface, whereas CFC-F1 shows a smooth surface formed by globular-shaped mosaics. From the AFM data, the film thicknesses of $196 \mathrm{~nm}$ for CFC-F1 and 72 $\mathrm{nm}$ for CFC-H1 were calculated, which is also in agreement with the better film formation capability of the CFC-F1 molecular system.

The creation of active layers endowed with intrinsic water repellency, which relieves the negative effects of moisture on the charged species produced under exercise conditions, ${ }^{51}$ has been recognized as an effective strategy for the enhancement of the long-term durability of optoelectronic devices. ${ }^{69}$ The static contact angle formed by a water drop standing on the film surface provides a direct estimate of the hydrophilic/hydrophobic properties of the surface, with water repellency increasing with the measured contact angle. ${ }^{70}$ Thus, a surface is commonly defined as hydrophilic if the value of the contact angle is less than $90^{\circ}$ and as hydrophobic if the value of the contact angle is greater than $90^{\circ} .{ }^{71}$ Comparison of the water contact angle values for the two CFC electropolymer films (Figure 4 and Table 1) clearly shows that the introduction of polyfluoroalkyl chain on the fluorene ring leads to a dramatic increase, from $82^{\circ}$ for CFC-H1 to $127^{\circ}$ for CFC-F1. The contact angle measured in the case of the CFC-H1 film is surprisingly low for an organic material that holds long hydrophobic alkyl chains in its chemical composition. This is due to an incomplete coverage of the ITO electrode, as evidenced in Figure 4. Thus, the electrodeposited CFC-H1 film does not efficiently shelter the substrate and the observed water contact angle is closer to that of the clean ITO surface, which corresponds to $75^{\circ}$. On the other hand, the superficial hydrophobic properties of the defect-free CFC-F1 film are typical of a polymeric material, characterized by the presence of polyfluoroalkyl residues. ${ }^{50,72,73}$ These results show that the introduction of polyfluoroalkyl side chains in fluorene/ carbazole hybrid monomers allows us to form by electro- 

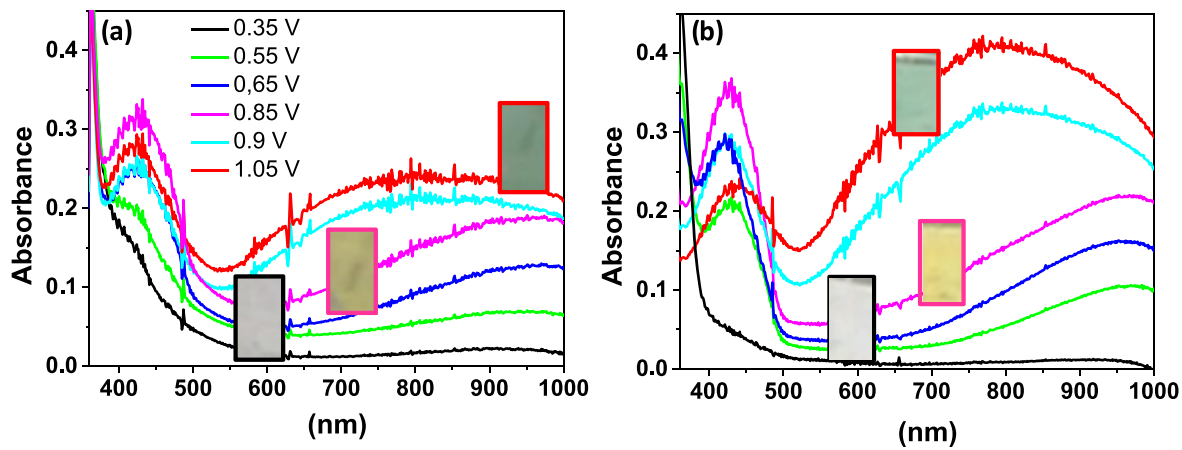

Figure 5. Spectroelectrochemical measurements of (a) CFC-H1 film (20 growth cycles) and (b) CFC-F1 film (five growth cycles) at different applied potentials. The potentials applied to obtain the different traces were the same for both monomers. The inset photographs show the electrode colorations at different redox states, and the color frame indicates the corresponding spectrum.

chemical techniques thin-film materials with good morphological and water repellency characteristics, which are highly desirable for the fabrication of optoelectronic devices.

Spectrolectrochemical Properties of Electrodeposited Films. To get information about the optoelectronic proprieties of the CFC electrodeposited films, spectroelectrochemical experiments were carried out on polymer films electrochemically generated over ITO electrodes applying the same experimental conditions used in the electrochemical studies described above. Nevertheless, for these spectroelectrochemical experiments, the film growth was adjusted by the applied number of potential cycles to optimize the film light absorption. The absorption spectra of the CFC films at different applied potentials are shown in Figure 5. The potential applied to each spectrum corresponds to the one identified with a dot of the same color in the corresponding film voltamperograms shown in Figure 3aII,bII. Both films present three redox states, being these neutral (partly transparent in the visible region of the electromagnetic spectrum), semioxidized (yellow), and fully oxidized (green). The inset pictures in Figure 5 show the CFC polymer film colorations at different oxidation states.

The electro-optical properties of the CFC film have their origin mainly in the carbazole dimer. The light absorption onset of the CFC-H1 and CFC-F1 films in their neutral state (light absorption spectra in black in Figure 5) is located at $\sim 404 \mathrm{~nm}$, as determined by the intersection between the projection of the light absorption band tail and the baseline. This UV band is due to the $\pi-\pi^{*}$ transition in the conjugated system, it has a maximum in the UV region at $\lambda \sim 340 \mathrm{~nm}$, close to the ITO optical cut, and therefore, it is not shown in Figure 5. However, both films in their neutral state shown a light absorption in the zone of $430 \mathrm{~nm}$, which can be assigned to the bicarbazole radicals cation. This would indicate that after the electrochemical film formation some positively charged traps remain. When the applied potential to the modified electrode reaches higher values than the film oxidation onset (see Table 1), two new electronic transitions are observed, one with peak maximum at $422 \mathrm{~nm}$ and another broader at $\sim 950 \mathrm{~nm}$ (see the green, blue, and magenta traces). In addition, when the potential advances through the second oxidation process of CFC films (see cyan and red dots and traces in Figures 3 and 5, respectively), the higher energy absorption band starts to decrease in absorbance intensity, whereas a new broad band at $800 \mathrm{~nm}$ is developed. This behavior is typical of electrodeposited carbazole-derivative materials, and these bands can be assigned to the formation of bicarbazole radical cations and dications by the oxidation of the polymeric film. ${ }^{23,48,61}$

\section{SUMMARY AND CONCLUSIONS}

We have developed two easily accessible electropolymerizable molecules that feature fluorene, bearing either alkyl or polyfluoroalkyl chains in the 9-position, as a bridge between two carbazole moieties. Adequate conditions for the growth of conductive polymers over platinum electrodes and over semitransparent ITO have been established. The proposed electropolymerization mechanism involves the reaction between two carbazole radical cations to form dicarbazole linkages between fluorene units. The morphological characteristics and the rate of deposition of the electropolymerized films generated in this process are heavily dependent on the nature of the pendant saturated chains on the fluorene bridge. In the case of polyfluoroalkyl chains (monomer CFC-F1), the film is homogeneous and very stable, with good adherence to the electrode surface. The nature of the pendant chains has also a deep impact on the water affinity of the films, which exhibit clear hydrophobic characteristics in the case of CFC-F1, as proved by static contact angle measurements. In addition, the materials obtained show electrochromic properties, with the coloration of the films switching from uncolored to green upon oxidation due to the applied potential. These findings open perspectives for application in the field of damp- or waterproofing optical coatings and the manufacture of intelligent windows.

\section{AUTHOR INFORMATION}

\section{Corresponding Authors}

*E-mail: gianluca.pozzi@istm.cnr.it (G.P.).

*E-mail: ffungo@exa.unrc.edu.ar (F.F.).

ORCID $\odot$

Simonetta Orlandi: 0000-0001-6783-4243

Maximiliano Andrés Zensich: 0000-0002-9425-4313

Fernando Fungo: 0000-0003-3291-0829

Notes

The authors declare no competing financial interest.

\section{ACKNOWLEDGMENTS}

We thank the CNR/Regione Lombardia project "Integrated Zero Emission Buildings", Consejo Nacional de Investigaciones Cientificas y Tecnicas (CONICET-Argentina), Agencia Nacional de Promoción Cientıfica y Tecnológica (ANPCYT Argentina), Universidad Nacional de Río Cuarto. M.V.C., 
G.M, M.A.Z, L.F, and F.F. are scientific members of CONICET.

\section{REFERENCES}

(1) Park, Y. W. Editorial for the Conducting Polymers for Carbon Electronics Themed Issue. Chem. Soc. Rev. 2010, 39, 2352-2353.

(2) Bujak, P.; Kulszewicz-Bajer, I.; Zagorska, M.; Maurel, V.; Wielgus, I.; Pron, A. Polymers for Electronics and Spintronics. Chem. Soc. Rev. 2013, 42, 8895-8999.

(3) Xie, L.-H.; Yang, S.-H.; Lin, J.-Y.; Yi, M.-D.; Huang, W. Fluorene-Based Macromolecular Nanostructures and Nanomaterials for Organic (Opto)Electronics. Philos. Trans. R. Soc., A 2013, 371, No. 20120337.

(4) Kiriy, A.; Pötzsch, R.; Wei, Q.; Voit, B. Voit, High-Tech Functional Polymers Designed for Applications in Organic Electronics, Polym. Degrad. Stab. Polym. Degrad. Stab. 2017, 145, $150-156$.

(5) Marrocchi, A.; Facchetti, A.; Lanari, D.; Petrucci, C.; Vaccaro, L. Current Methodologies for a Sustainable Approach to $\pi$-Conjugated Organic Semiconductors, Energy Environ. Energy Environ. Sci. 2016, $9,763-786$.

(6) Schroot, R.; Jäger, M.; Schubert, U. S. Synthetic Approaches towards Structurally-Defined Electrochemically and (Photo)RedoxActive Polymer Architectures. Chem. Soc. Rev. 2017, 46, 2754-2798.

(7) Ahmad, S.; Ikeda, T. Electroactive Coatings: For Electrically Controlled on Demand Power Windows. Nanosci. Nanotechnol. Lett. 2013, 5, 3-12.

(8) Wang, Y.; Runnerstrom, E. L.; Milliron, D. J. Switchable Materials for Smart Windows. Annu. Rev. Chem. Biomol. Eng. 2016, 7, 283-304.

(9) Li, G.; Zhu, R.; Yang, Y. Polymer Solar Cells. Nat. Photon. 2012, $6,153-161$

(10) Gendron, D.; Leclerc, M. New Conjugated Polymers for Plastic Solar Cells. Energy Environ. Sci. 2011, 4, 1225-1237.

(11) Facchetti, A. $\pi$-Conjugated Polymers for Organic Electronics and Photovoltaic. Chem. Mater. 2011, 23, 733-758.

(12) Xiao, S.; Zhang, Q.; You, W. Molecular Engineering of Conjugated Polymers for Solar Cells: An Updated Report. Adv. Mater. 2017, 29, No. 1601391.

(13) Park, M.-H.; Han, T.-H.; Kim, Y.-H.; Jeong, S.-H.; Lee, Y.; Seo, H.-K.; Cho, H.; Lee, T.-W. Flexible Organic Light-Emitting Diodes for Solid-State Lighting. J. Photon. Energy 2015, 5, No. 053599.

(14) Boudreault, P.-L. T.; Beaupré, S.; Leclerc, M. Polycarbazoles for Plastic Electronics. Polym. Chem. 2010, 1, 127-136.

(15) Dumur, F. Carbazole-Based Polymers as Hosts for SolutionProcessed Organic Light-Emitting Diodes: Simplicity, Efficacy. Org. Electron. 2015, 25, 345-361.

(16) Sathiyan, G.; Sivakumar, E. K. T.; Ganesamoorthy, R.; Thangamuthu, R.; Sakthivel, P. Review of Carbazole Based Conjugated Molecules for Highly Efficient Organic Solar Cell Application. Tetrahedron Lett. 2016, 57, 243-252.

(17) Heredia, D.; Natera, J.; Gervaldo, M.; Otero, L.; Fungo, F.; Lin, C.-Y.; Wong, K.-T. Spirobifluorene-Bridged Donor/Acceptor Dye for Organic Dye-Sensitized Solar Cells. Org. Lett. 2010, 12, 12-15.

(18) Abbel, R.; Schenning, A. P. H. J.; Meijer, E. W. Fluorene-Based Materials and Their Supramolecular Properties. J. Polym. Sci., Part A: Polym. Chem. 2009, 47, 4215-4233.

(19) Yu, M.; Ou, C.; Liu, B.; Lin, D.; Liu, Y.; Xue, W.; Lin, Z.; Lin, J.; Qian, Y.; Wang, S.; et al. Progress in Fluorene-Based WideBandgap Steric Semiconductors. Chin. J. Polym. Sci. 2017, 35, 155170.

(20) Fungo, F.; Wong, K.-T.; Ku, S.-Y.; Hung, Y.-Y.; Bard, A. J. Electrogenerated Chemiluminescence. 81. Influence of Donor and Acceptor Substituents on the ECL of a Spirobifluorene-Bridged Bipolar System. J. Phys. Chem. B 2005, 109, 3984-3989.

(21) Heredia, D.; Fernandez, L.; Otero, L.; Ichikawa, M.; Lin, C. Y.; Liao, Y. L.; Wang, S. A.; Wong, K. T.; Fungo, F. Electrochemical Tuning of Morphological and Optoelectronic Characteristics of Donor-Acceptor Spiro-Fluorene Polymer Film. Application in the
Building of an Electroluminescent Device. J. Phys. Chem. C 2011, 115, 21907-21914.

(22) Zabel, P.; Dittrich, T.; Liao, Y.-L.; Lin, C.-Y.; Wong, K.-T.; Fungo, F.; Fernandez, L.; Otero, L. Engineering of Gold Surface Work Function by Electrodeposition of Spirobifluorene Donor-Acceptor Bipolar Systems. Org. Electron. 2009, 10, 1307-1313.

(23) Promarak, V.; Saengsuwan, S.; Jungsuttiwong, T.; Sudyoadsuk, T.; Keawin, T. Synthesis and Characterization of N-Carbazole EndCapped Oligofluorenes. Tetrahedron Lett. 2007, 48, 89-93.

(24) Usluer, O.; Demic, S.; Egbe, D. A. M.; Birckner, E.; Tozlu, C.; Pivrikas, A.; Ramil, A. M.; Sariciftci, N. S. Fluorene-Carbazole Dendrimers: Synthesis, Thermal, Photophysical and Electroluminescent Device Properties. Adv. Funct. Mater. 2010, 20, 4152-4161.

(25) Koyuncu, S.; Usluer, O.; Can, M.; Demic, S.; Icli, S.; Sariciftci, N. S. Electrochromic and Electroluminescent Devices Based on a Novel Branched Quasi-Dendric Fluorene-Carbazole-2,5-Bis(2-Thienyl)-1H-Pyrrole System. J. Mater. Chem. 2011, 21, 2684-2693.

(26) Meunmart, D.; Prachumrak, N.; Keawin, T.; Jungsuttiwong, S.; Sudyoadsuk, T.; Promarak, V. Bis(4-Diphenylaminophenyl)Carbazole End-Capped Fluorene as Solution-Processed Deep-Blue LightEmitting and Hole-Transporting Materials for Electroluminescent Devices, Tetrahedron Lett. Tetrahedron Lett. 2012, 53, 3615-3618.

(27) Sangchart, T.; Niroram, A.; Kaewpuang, T.; Prachumrak, N.; Namuangruk, S.; et al. Synthesis, Physical and Electroluminescence Properties of 3,6-Dipyrenylcarbazole End Capped Oligofluorenes. RSC Adv. 2015, 5, 26569-26579.

(28) Sarac, A. S. Electropolymerization. Encyclopedia of Polymer Science and Technology; John Wiley \& Sons, Inc.: Hoboken, NJ, 2004.

(29) Yan, H.; Kurogi, K.; Mayama, H.; Tsujii, K. Environmentally Stable Super Water-Repellent Poly(Alkylpyrrole) Films. Angew. Chem., Int. Ed. 2005, 44, 3453-3456.

(30) Nicolas, M.; Guittard, F.; Géribaldi, S. Stable Superhydrophobic and Lipophobic Conjugated Polymers Films. Langmuir 2006, 22, 3081-3088.

(31) Mortier, C.; Darmanin, T.; Guittard, F. 3,4-Dialkoxypyrrole for the Formation of Bioinspired Rose Petal-like Substrates with High Water Adhesion. Langmuir 2016, 32, 12476-12487.

(32) Mortier, C.; Darmanin, T.; Guittard, F. Direct Electrodeposition of Superhydrophobic and Highly Oleophobic Poly(3,4Ethylenedioxypyrrole) (PEDOP) and Poly(3,4-Propylenedioxypyrrole) (PProDOP) Nanofibers. ChemNanoMat 2017, 3, 885-894.

(33) Darmanin, T.; Taffin de Givenchy, E.; Amigoni, S.; Guittard, F. Hydrocarbon versus Fluorocarbon in the Electrodeposition of Superhydrophobic Polymer Films. Langmuir 2010, 26, 17596-17602.

(34) Darmanin, T.; Taffin de Givenchy, E.; Guittard, F. Superhydrophobic Surfaces of Electrodeposited Polypyrroles Bearing Fluorinated Liquid Crystalline Segments. Macromolecules 2010, 43, 9365-9370.

(35) Darmanin, T.; Guittard, F. Superhydrophobic Fiber Mats by Electrodeposition of Fluorinated Poly(3,4-Ethyleneoxythiathiophene). J. Am. Chem. Soc. 2011, 133, 15627-15634.

(36) Bellanger, H.; Darmanin, T.; Guittard, F. Surface Structuration (Micro and/or Nano) Governed by the Fluorinated Tail Lengths toward Superoleophobic Surfaces. Langmuir 2012, 28, 186-192.

(37) Sulaiman, Y.; Kataky, R. Effect of Monomer Modifications on the Physical Properties of Electropolymerised PEDOT Films. J. Electrochem. Soc. 2011, 159, F1-F9.

(38) Bellanger, H.; Darmanin, T.; de Givenchy, E. T.; Guittard, F. Influence of Long Alkyl Spacers in the Elaboration of Superoleophobic Surfaces with Short Fluorinated Chains. RSC Adv. 2013, 3, 5556-5562.

(39) Mortier, C.; Darmanin, T.; Guittard, F. The Major Influences of Substituent Size and Position of 3,4-Propylenedioxythiophene on the Formation of Highly Hydrophobic Nanofibers. ChemPlusChem 2014, 79, 1434-1439.

(40) Darmanin, T.; Guittard, F. Highly Polar Linkers (Urea, Carbamate, Thiocarbamate) for Superoleophobic/Superhydrophobic or Oleophobic/Hydrophilic Properties. Adv. Mater. Interfaces 2015, 2, No. 1500081 
(41) Natera, J.; Otero, L.; Sereno, L.; Fungo, F.; Wang, N.-S.; Tsai, Y.-M.; Hwu, T.-Y.; Wong, K.-T. A Novel Electrochromic Polymer Synthesized through Electropolymerization of a New DonorAcceptor Bipolar System. Macromolecules 2007, 40, 4456-4463.

(42) Natera, J.; Otero, L.; D’Eramo, F.; Sereno, L.; Fungo, F.; Wang, N.-S.; Tsai, Y.-M.; Wong, K.-T. Synthesis and Properties of a Novel Cross-Linked Electroactive Polymer Formed from a Bipolar Starburst Monomer. Macromolecules 2009, 42, 626-635.

(43) Usluer, O.; Koyuncu, S.; Demic, S.; Raj, J. A Novel Highcontrast Ratio Electrochromic Material from Spiro[Cyclododecane1,9'-fluorene]Bicarbazole. J. Polym. Sci., Part B: Polym. Phys. 2011, 49, 333-341.

(44) Lv, Y.; Yao, L.; Gu, C.; Xu, Y.; Zhang, Y.; Xie, Z.; Liu, L.; Ma, Y. Cross-Linked Luminescent Films via Electropolymerization of Multifunctional Precursors for Highly Efficient Electroluminescence. Polym. Chem. 2013, 4, 2090-2096.

(45) Yu, T.; Wu, X.; Lv, Y.; Liu, L.; Du, L.; Zhou, J.; Xie, Z.; Ma, Y. An Electrochemically Deposited Film as an Interface Layer to Improve the Performance of Polymer Light-Emitting Diodes. J. Mater. Chem. C 2014, 2, 4117-4120.

(46) Ambrose, J. F.; Nelson, R. F. Anodic Oxidation Pathways of Carbazoles: I. Carbazole and N-Substituted Derivatives. J. Electrochem. Soc. 1968, 115, 1159-1164.

(47) Morin, J.-F.; Leclerc, M.; Adès, D.; Siove, A. Polycarbazoles: 25 Years of Progress. Macromol. Rapid Commun. 2005, 26, 761-778.

(48) Mangione, M. I.; Spanevello, R. A.; Minudri, D.; Heredia, D.; Fernandez, L.; Otero, L.; Fungo, F. Electropolimerization of Functionalizaed Carbazole End-Capped Dendrimers. Formation of Conductive Films. Electrochim. Acta 2016, 207, 143-151.

(49) Mangione, M. I.; Spanevello, R. A.; Minudri, D.; Cavallo, P.; Otero, L.; Fungo, F. Electrochemical Films Deposition and ElectroOptical Properties of Bis-Carbazol-Triphenylamine End-Caped Dendrimeric Polymers. Electrochim. Acta 2018, 263, 585-595.

(50) Améduri, B.; Boutevin, B. Well-Architectured Fluoropolymers: Synthesis, Properties and Applications; Elsevier: Amsterdam, 2004.

(51) So, F.; Kondakov, D. Degradation Mechanisms in SmallMolecule and Polymer Organic Light-Emitting Diodes. Adv. Mater. 2010, 22, 3762-3777.

(52) Babudri, F.; Farinola, G. M.; Naso, F.; Ragni, R. Fluorinated Organic Materials for Electronic and Optoelectronic Applications: The Role of the Fluorine Atom. Chem. Commun. 2007, 1003-1022.

(53) Kameshima, H.; Nemoto, N.; Endo, T. Synthesis and Properties of Fluorene-based Fluorinated Polymers. J. Polym. Sci., Part A: Polym. Chem. 2001, 39, 3143-3150.

(54) Amara, J. P.; Swager, T. M. Conjugated Polymers with Geminal Trifluoromethyl Substituents Derived from Hexafluoroacetone, Macromolecules. Macromolecules 2006, 39, 5753-5759.

(55) Ohkubo, K.; Sakamoto, Y.; Suzuki, T.; Tsuzuki, T.; Kumaki, D.; Tokito, S. Synthesis, Structure, and Transport Property of Perfluorinated Oligofluorenes. Chem. - Eur. J. 2008, 14, 4472-4474.

(56) Darmanin, T.; Nicolas, M.; Guittard, F. Synthesis and Properties of Perfluorinated Conjugated Polymers Based on Polyethylenedioxythiophene, Polypyrrole, and Polyfluorene. Toward Surfaces with Special Wettabilities. Langmuir 2008, 24, 9739-9746.

(57) Lee, J.-K.; Fong, H. H.; Zakhidov, A. A.; McCluskey, G. E.; Taylor, P. G.; et al. Semiperfluoroalkyl Polyfluorenes for Orthogonal Processing in Fluorous Solvents. Macromolecules 2010, 43, 11951198.

(58) Fong, H. H.; Lee, J. K.; Lim, Y. F.; Zakhidov, A. A.; Wong, W. W. H.; Holmes, A. B.; Ober, C. K.; Malliaras, G. G. Orthogonal Processing and Patterning Enabled by Highly Fluorinated LightEmitting Polymers. Adv. Mater. 2011, 23, 735-739.

(59) Chaikovskii, V. K.; Filimonov, V. D.; Funk, A. A.; Skorokhodov, V. I.; Ogorodnikov, V. D. 1,3-Diiodo-5,5-Dimethylhydantoin-An Efficient Reagent for Iodination of Aromatic Compounds. Russ. J. Org. Chem. 2007, 43, 1291-1296.

(60) Cardona, C. M.; Li, W.; Kaifer, A. E.; Stockdale, D.; Bazan, G. C. Electrochemical Considerations for Determining Absolute Frontier
Orbital Energy Levels of Conjugated Polymers for Solar Cell Applications. Adv. Mater. 2011, 23, 2367-2371.

(61) Ohkita, H.; Ito, S.; Yamamoto, M.; Tohda, Y.; Tani, K. Intramolecular Excimer Emissions of Syn- and Anti-[3.3](3,9)Carbazolophanes in Solutions. J. Phys. Chem. A 2002, 106, 21402145.

(62) Cho, Y.-J.; Wee, K.-R.; Son, H.-J.; Cho, D. W.; Kang, S. O. A Detailed Investigation of Light-Harvesting Efficiency of Blue Color Emitting Divergent Iridium Dendrimers with Peripheral Phenylcarbazole Units. Phys. Chem. Chem. Phys. 2014, 16, 4510-4521.

(63) Ray, K.; Misra, T. N. Spectroscopic Study of Nonamphiphilic 9Phenylcarbazole Assembled in Langmuir-Blodgett Films. Langmuir 1997, 13, 6731-6736.

(64) Adhikari, R. M.; Mondal, R.; Shah, B. K.; Neckers, D. C. Synthesis and Photophysical Properties of Carbazole-Based Blue Light-Emitting Dendrimers. J. Org. Chem. 2007, 72, 4727-4732.

(65) Berlman, I. Handbook of Florescence Spectra of Aromatic Molecules; Elsevier, 2012.

(66) Vincent, J.-M. Recent Advances of Fluorous Chemistry in Material Sciences. Chem. Commun. 2012, 48, 11382-11391.

(67) Li, M.; Tang, S.; Shen, F.; Liu, M.; Xie, W.; Xia, H.; Liu, L.; Tian, L.; Xie, Z.; Lu, P.; et al. Electrochemically Deposited Organic Luminescent Films: The Effects of Deposition Parameters on Morphologies and Luminescent Efficiency of Films. J. Phys. Chem. B 2006, 110, 17784-17789.

(68) Kang, B.; Kim, R.; Lee, S. B.; Kwon, S.-K.; Kim, Y.-H.; Cho, K. Side-Chain-Induced Rigid Backbone Organization of Polymer Semiconductors through Semifluoroalkyl Side Chains. J. Am. Chem. Soc. 2016, 138, 3679-3686.

(69) Cho, K. T.; Zhang, Y.; Orlandi, S.; Cavazzini, M.; Zimmermann, I.; Lesch, A.; Tabet, N.; Pozzi, G.; Grancini, G.; Nazeeruddin, M. K. Water-Repellent Low-Dimensional Fluorous Perovskite as Interfacial Coating for $20 \%$ Efficient Solar Cells. Nano Lett. 2018, 18, 5467-5474.

(70) Palumbo, F.; Mundo, R. D. Wettability: Significance and Measurement. In Polymer Surface Characterization; Sabbatini, L., Ed.; De Gruyter: Berlin, 2014; pp 207-245.

(71) Zhang, X.; Shi, F.; Niu, J.; Jiang, Y.; Wang, Z. Superhydrophobic Surfaces: From Structural Control to Functional Application. J. Mater. Chem. 2008, 18, 621-633.

(72) Honda, K.; Morita, M.; Sakata, O.; Sasaki, S.; Takahara, A. Effect of Surface Molecular Aggregation State and Surface Molecular Motion on Wetting Behavior of Water on Poly(Fluoroalkyl Methacrylate) Thin Films. Macromolecules 2010, 43, 454-460.

(73) Pevzner, L.; Auer, M.; Trattnig, R.; Klapper, M.; ListKratochvil, E. J. W.; Müllen, K. Controlling Polymer Solubility: Polyfluorenes with Branched Semiperfluorinated Side Chains for Polymer Light-Emitting Diodes. Isr. J. Chem. 2014, 54, 736-747. 